\title{
Why Macroeconomics does not Supervene on Microeconomics
}

\author{
BRIAN EPSTEIN
}

Journal of Economic Methodology 21, No. 1

(2014), 3-18.

In recent years, the project of providing microeconomic foundations for macroeconomics has taken on new urgency. Some philosophers and economists have challenged the project, both for the way economists actually approach microfoundations and for more general antireductionist reasons. Reductionists and anti-reductionists alike, however, have taken it to be trivial that the macroeconomic facts are exhaustively determined by microeconomic ones. In this paper, I challenge this supposed triviality. I argue that macroeconomic properties do not even globally supervene on microeconomic ones. This is simply a consequence of the difference in the explanatory goals of the respective fields, which implicitly carve out the microeconomic property set in such a way that it underdetermines macroeconomic properties. It means, however, that microeconomics-based foundations for macroeconomics are inadequate in principle.

\section{Introduction}

Since Robert Lucas's 1976 critique of macroeconomic policymaking, much effort has been dedicated to the development of "microfoundations" for macroeconomics. ${ }^{1}$ In recent years, a number of previously independent streams

${ }^{1}$ General equilibrium theory had historically been so idealized that few lessons could be drawn about the relations among macrovariables in a real economy. Even Arrow and Hahn 1971 suggest that the key lesson of investigating the properties of equilibria is to provide assurance of the possibility of arriving at equilibrium in a complex system, rather than being useful for macroeconomic policy (Cf. Hausman 1992). 
of microeconomic modeling - e.g., models of risk and incomplete information, incomplete markets, monetary phenomena, price and labor inflexibility, and departures from rationality - have begun to converge. Among these newly integrated models are real business cycle models, new Keynesian models, and others now falling under the rubric of dynamic stochastic general equilibrium (DSGE) theory. These advances have seemed to many people to hold great promise in delivering genuine microeconomic models of macroeconomic properties.

Nonetheless, there remains a good deal of skepticism among philosophers of economics with respect to the microfoundations project. The most common criticisms have been leveled against the use of "representative agents" in these models. ${ }^{2}$ Representative agent models have been criticized by a number of economists and philosophers, including Kirman, Nelson, Janssen, Hartley, Kincaid, and Hoover. ${ }^{3}$ Criticism of representative agent models is often part of a larger critique of microfoundations as well. Many philosophers and economists are pluralists about explanation, and doubt the utility or necessity of microfoundations. It is not universally held that useful or robust or explanatory macroeconomic models do require microfoundations, despite Lucas's arguments.

A stronger critical stance is to doubt the possibility of microfoundations for

2 This involves treating agents as an aggregate of homogeneous "representative" individuals, which has properties averaged over the population. Without idealizing agents as a representative agent, the problem of aggregating individual preferences and consumption is often analytically intractable.

3 Nelson 1986; Kirman 1992; Janssen 1993; Hartley 1997; Kincaid 1997; Hoover 2001a; Hoover 2006. The self-conscious employer of the representative agent model holds out the hope that even though it is possible for aggregated preferences to be ill-behaved, that they will not be. A critic will regard representative agent models to be poor idealizations, but different skeptics may draw diametrically opposed conclusions from this. Some hold that it militates for a more sophisticated approach to microfoundations, and indeed, some recent work on DSGE models has begun to incorporate heterogeneous agents. Others hold that it is evidence that microfoundational projects are a pipe dream. 
macroeconomics altogether. This sort of skepticism is often based on similar considerations as skepticism about reduction in other special sciences. Arguments against reducibility of a high level domain (“domain A”) on a lowlevel domain ("domain B") typically hold that there is a gap between (1) the ontological determination of entities and properties in domain A by entities and properties in domain $\mathrm{B}$, and (2) the explainability or identification of events or generalizations in domain $\mathrm{A}$ in terms of those in domain B. It is commonly conceded, for instance, that chemical properties supervene on those of physics, but that nonetheless there may be barriers to the reduction of chemical properties to the properties of physics.

Arguments for the compatibility of supervenience with non-reducibility are by now familiar enough that they have become the default route for skepticism about reduction. Many anti-reductionists about macroeconomics, in fact, emphasize the supervenience of macroeconomics on microeconomics, on their way to pointing out that supervenience does not entail reducibility. For instance, Hoover 1995 and Kincaid 1998 both stress this point: they argue against the reducibility of macroeconomics to microeconomics, while holding that macroeconomics does supervene on microeconomics.

Since one can deny the reducibility of theories of domain A to theories of domain $\mathrm{B}$ without denying the supervenience of domain $\mathrm{A}$ on domain $\mathrm{B}$, it is rare even to bother assessing the supervenience claim. ${ }^{4}$ As applied to economics, it is almost universally held that while the provision of microfoundations for macroeconomics is difficult in practice if not impossible in principle, nonetheless the supervenience of macroeconomic phenomena on microeconomic phenomena is trivial. ${ }^{5}$

\footnotetext{
${ }^{4}$ In some cases this claim has been discussed at length, such as in teleofunctional accounts of biological properties, which deny that certain biological properties supervene on synchronic supervenience bases.

${ }^{5}$ Not everyone assumes it is trivial. Kevin Hoover explicitly argues for supervenience and against reducibility, in Hoover 1995; Hoover 2001b; Hoover 2001a; Hoover 2006. And as I discuss below, Julian Reiss challenges it.
} 
My aim in this paper is to argue that this supposed triviality is in fact false. Microeconomic properties fail to exhaustively determine the macroeconomic properties.

This claim, it may seem, is absurd, heretical, mysterious. If microeconomic properties do not suffice to determine the macroeconomic ones, what does? The spirit of society? But the point is not particularly mysterious, nor does it mean that macroeconomics is ontologically "free-floating" or that it involves a dualistic ontology or some Hegelian spirit-world. It is rare, in fact, for one special science to supervene on another special science. Supervenience failure is simply a consequence of the difference in the explanatory goals of the respective fields, which implicitly carve out the microeconomic property set in such a way that it underdetermines macroeconomic properties. This is not a shortcoming, but a reasonable outcome of the implicit design principles behind microeconomics. Clarifying the different goals of micro and macroeconomics, we should not even expect macroeconomics to supervene on microeconomics. That is not to say that microeconomics could not be expanded, beyond the way it is currently conceived of and practiced. An appropriate expansion of the domain of microeconomics - and correspondingly, the set of properties that count as the microeconomic ones - could suffice for macroeconomics to supervene on it. It is beyond the scope of this paper to consider how and whether microeconomics could be reasonably expanded in this way, and what tradeoffs such an expansion might involve. The aim of the present argument is to take a generous but realistic picture of the domain of microeconomics as it is practiced and conceived of, and show that the domain of macroeconomics does not supervene on it.

Elsewhere I have argued for a different but related claim, so let me point out the contrast up front. In Epstein 2009, I argue against the thesis of “ontological individualism," i.e., against the claim that social properties supervene on individualistic properties. The claim and the strategy in that paper are related to this one, but there are important differences. One difference, of course, is that not all social properties are macroeconomic properties, so it is possible for ontological individualism to fail even if all macroeconomic 
properties supervene on individualistic properties. More important, however, is that the microeconomic properties are plausibly a bigger set than the individualistic properties. Some people, for instance, construe individualism to involve only the psychological properties of individual people. Some construe it to involve only intrinsic properties. Some have broader conceptions of what individualistic properties are. But there can be no doubt that microeconomic properties include not just people, but our resource bundles, certain things we come in contact with, and so on.

In short, because the set of macroeconomic properties (our domain A) is plausibly a subset of the social properties, and because the set of microeconomic properties (our domain B) is plausibly a superset of the individualistic properties, it could easily be the case that macroeconomics does supervene on microeconomics, even granting that all the arguments in Epstein 2009 are correct. To evaluate whether macroeconomics supervenes on microeconomics, we have to actually look at the sciences and their domains, and extract an understanding of what the supervenience claim is and how the supervenience base in particular should be construed.

\section{Preliminaries on supervenience}

It is generally agreed that the supervenience relation is a useful way of understanding important necessary conditions for the "exhaustive determination" of a set of properties by another set. ${ }^{6}$ There are, however, many varieties of supervenience, so in evaluating the supervenience of macroeconomic properties on microeconomic ones, we need to be clear on which variety is involved in the claim. Although the most common form of

${ }^{6}$ Supervenience is not generally regarded as sufficient to capture the full "ontological dependence” relation, as supervenience involves a modal covariation, while ontological dependence arguably involves essentiality rather than only necessity (cf. Fine 1994). Still, modal covariation seems to be a necessary even if insufficient condition for ontological dependence. 
supervenience is local supervenience, ${ }^{7}$ it is widely recognized that social properties do not locally supervene on individualistic properties in general. ${ }^{8}$ And the same arguments easily apply to economic properties, so it turns out to be rather obvious that macroeconomic properties do not locally supervene on microeconomic ones. Instead, to interpret the claim of determination and exhaustion of macroeconomics by microeconomics charitably, it should be taken to involve the weaker claim of global supervenience.

On Jaegwon Kim's definition, A-properties supervene globally on Bproperties just in case if two worlds $\mathrm{w}_{1}$ and $\mathrm{w}_{2}$ are as a whole B-indiscernible, then they are A-indiscernible. ${ }^{9}$ To apply it to the present case: Macroeconomic properties globally supervene on microeconomic properties just in case if two worlds $\mathrm{w}_{1}$ and $\mathrm{w}_{2}$ are microeconomically indiscernible, then they are macroeconomically indiscernible. To test for supervenience, we must set up two worlds or circumstances that have the same microeconomic properties and show that nonetheless they may have different macroeconomic properties.

We often speak of the supervenience of a scientific field on another scientific field, such as of psychology on neurology, or chemistry on physics. To be precise, however, supervenience is not a relation between theories or sets of theories. Instead, it is usually understood as a relation between sets of properties and other sets of properties. ${ }^{10}$ This becomes a complication when we

${ }^{7}$ On Jaegwon Kim's definition, A-properties supervene locally on B-properties just in case for every pair of objects $\mathrm{x}$ and $\mathrm{y}$, if $\mathrm{x}$ and $\mathrm{y}$ are B-indiscernible then they are Aindiscernible. Cf. Kim 1984. This is also known as “individual supervenience,” but that term is potentially confusing in the present context.

${ }^{8}$ Currie 1984; Pettit 2003; Epstein 2009.

9 There is a variety of interpretations of global supervenience, turning on how we are to understand the indiscernibility of worlds. (Cf. Sider 1999; Bennett 2004; Shagrir 2002). But discriminating among these complicates the discussion, and all of them will fail for the same reason, in the present context.

${ }^{10}$ Some audiences encountering this material have been unclear about this point. The most widely used definitions of supervenience are in Kim 1984 and Kim 1987. McLaughlin and Bennett give an excellent overview of the variants of supervenience in McLaughlin 
deal with a field or approach or sort of theory like microeconomics, whose domain is not well specified. In many ways, the crux of the issue is figuring out what the microeconomic properties are — that is, the "supervenience base" on which macroeconomic properties are taken to supervene. ${ }^{11}$ If the set of microeconomic properties is too broadly understood, then it can even be stretched so far as to trivialize any reduction claims. If it is too narrowly understood, on the other hand, then a supervenience claim will fail without being given a fair chance.

and Bennett 2005. Some people have wondered if it is not events, rather than properties, that are typically taken to as the sets of supervening and subvening entities. In his early discussions of supervenience, Davidson does in fact speak of the supervenience of events; but he glosses it in terms of property supervenience. Kim has likewise spoken of fact supervenience, but again glosses it in terms of property supervenience. The supervenience of objects is also typically cast in terms of property supervenience, for a given object $\mathrm{N}$ employing the identity property being $N$. Other people have worried about talk of properties, and are more comfortable speaking of economic predicates rather than properties. Since predicates are linguistic items, however, there are two ways of understanding what we might mean by the supervenience of predicates. The reasonable way again is as property supervenience, where we take predicates to refer to properties, and then understand the supervenience of a predicate-set on another predicate-set as the supervenience of the set of properties denoted by the first predicateset on the set of properties referred to by the second. If someone is genuinely interested in the supervenience of predicates themselves, then since predicates are linguistic items this will be a question for linguistics, rather than the relation between two domains of economics.

${ }^{11}$ Similarly, if we are interested, for instance, in assessing whether a biological property holding at time t supervenes on chemistry, then it becomes important to determine whether the facts about chemistry or the chemical properties in question include only the chemical properties of the world at $t$, or the chemical properties at the times preceding $t$ as well. If biological properties are historical, as many philosophers of biology have taken them to be, then they clearly will require historical properties to be included in the supervenience base as well. Clarifying just what the chemical properties are is the greatest part of ascertaining whether biological properties do or do not supervene on them. 
In a review of Kevin Hoover's The Methodology of Empirical Macroeconomics, Julian Reiss presents the only explicit challenge of which I am aware to the supervenience of macroeconomics on microeconomics. ${ }^{12}$ It is helpful to consider the problems with Reiss's understanding of supervenience, so as to clarify exactly what the supervenience claim involves and what it does not. ${ }^{13}$ Reiss makes two points against the supervenience claim:

One point is that, clearly, macro entities causally influence micro entities (when, for example, agents react to inflation or recessions or changes in the federal funds rate). This contradicts both the spirit and the letter of supervenience theories.

The second point is that it is not clear whether one would really "fix" the macro entities by "fixing" the micro entities... this is due to the liberty with which macro aggregates are constructed. There is no one way in which, say, the price level can be measured. Importantly, different ways of measuring have different, and in some cases very different, results. These results, in turn, may have effects that spread throughout the economy... Even if one assumes strict determinism at the micro level, copying a microeconomy would not ensure that the history of the duplicate would be identical to the history of the original. In order to ensure that, one would also have to fix the methods of measurement, but this is exactly the "additional bit" macro entities have and whose existence supervenience theorists deny. ${ }^{14}$

On the first point, Reiss is mistaken that the ability of macro entities to have causal effects on micro entities is incompatible with, or even in tension with, the letter or spirit of supervenience. For instance, changes in the chemical properties of a bar of iron cause changes in the magnetic fields surrounding the iron, but that does not imply that chemical properties fail to supervene on

\footnotetext{
${ }^{12}$ Reiss 2004

${ }^{13}$ Kevin Hoover has also responded to Reiss in a recent paper (Hoover 2009), pointing out some different issues than I do here.

${ }^{14}$ Reiss 2004, pp. 232-233.
} 
physical ones. ${ }^{15}$

On the second point, the supervenience theorist would presumably allow that historical properties are included in both the microeconomic and macroeconomic supervenience bases. Some theorists might postulate that macroeconomic properties of an entity at time $t$ supervene on its microeconomic properties at $t$, but that is not required for a global supervenience claim to hold, on a plausible understanding of the micro- and macroeconomic property sets. Moreover, assessing a supervenience claim involves determining whether two worlds, $w_{1}$ and $w_{2}$, exemplify the same macroeconomic properties, not whether the inhabitants of the worlds would ascribe the properties to their own situations. A supervenience claim involves the prior delineation of the sets of A-properties and B-properties, which are evaluated across worlds. Reiss states that the effects of a choice of measurement systems, by which macroeconomic properties are chosen, can spread through an economy. But in this case, then either they spread in a way that makes the worlds microeconomically discernible, in which case the worlds are not B-indiscernible in the first place, or else it does not make them microeconomically discernible, in which case it is irrelevant to the supervenience claim whether the inhabitants of the world would ascribe those properties to themselves or not. ${ }^{16}$

${ }^{15}$ It may be thought that the "causal exclusion" argument, advanced by Kim and others (e.g. Kim 1998; Kim 2001) provides some reason to believe in this incompatibility, but this is not correct. The causal exclusion argument involves the incompatibility of five intuitive theses, including both a supervenience and an exclusion thesis. However, the four theses even apart from the supervenience thesis are already mutually inconsistent. (Cf. Kallestrup 2006). Moreover, proponents of the argument diagnose it as implying the failure of one of the other four theses, since it is generally discussed in connection with mental causation, and few would deny the supervenience of the mental on the physical.

${ }^{16}$ Hoover points out that certain macroeconomic properties, such as price index levels, may be interpreted in multiple equally useful ways (Hoover 2001a, Hoover 2009). This, however, is compatible with any precisification of such properties still supervening on microeconomic ones. 
Supervenience can thus not be dispensed with so easily. To assess and criticize the claim of supervenience, it must be shown that there can be two situations having exactly the same microeconomic properties, but yet having different macroeconomic properties. The difference cannot be due to a difference in how the properties are defined or understood in the two situations, but rather be based on the fact that macroeconomic properties simply depend on factors beyond the microeconomic ones in the situations.

And, as I mentioned, endorsing supervenience is compatible with rejecting reducibility. It is a standard move for anti-reductionists such as Hoover to endorse supervenience claims, so as to grant the exhaustive determination of the higher-level property set by the lower-level one, while nonetheless arguing that that determination does not imply reducibility.

It is important to note that although supervenience does not entail reducibility, the entailment does hold in the other direction. For a theory of micro-properties to provide microfoundations for a given theory of macroproperties, the macro-properties must supervene on the micro-properties. To see this, suppose that supervenience failed. That means that the macroproperties could change without any change in the micro-properties. Suppose such a change were modeled in the macro-theory. Then, even if we had a "perfect" theory of the micro-level, the micro-level theory would not be able to capture that macro-level change. So the micro-theory would not be able to provide microfoundations for the macro-theory.

The failure of macroeconomic facts or properties to supervene on microeconomic ones is thus a significant and far-reaching claim. The failure of supervenience implies the failure of microfoundations. It also implies that there is an important disanalogy between economics and at least certain natural sciences: higher-level disciplines like chemistry do plausibly supervene on lower-level ones like physics, but the analogous point does not hold for economics.

\section{Delineating microeconomics}

To see how we might characterize the domain of a special science, and 
evaluate whether one special science supervenes on another, let us consider a case of supervenience failure and one of success, both outside of economics.

\subsection{Supervenience failure and success}

Rudolf Virchow, the famous advocate of cell theory in the $19^{\text {th }}$ century, believed that living organisms are composed exclusively of cells. ${ }^{17}$ Organisms simply are aggregates of cells, and therefore the characteristics of organisms — their development, operation, and pathology — should be explained in terms of the characteristics of cells. To put it in our terms, he endorsed the supervenience of anatomical properties on cytological properties. Cytological properties are the properties a cell might have, or relations that might hold at a cellular level. They include such properties as being cytoplasm, having a cellular membrane with such-and-such composition, having such-and-such organelles, and so on. Anatomical properties might include the hip bone being connected to the leg bone, being the digestive system, and so on.

If we actually take a look at the composition of a human or other organism, however, it turns out that a great deal of it is not cellular at all. Outside of cytoplasm, organelles, and cell membranes are large swaths of extracellular material. Bone matrix, for instance, and blood plasma, gastric fluids, cerebrospinal fluid, the gelatinous goo in the eye, regions of urine and bile. Cells, to be sure, are critically important to people, but the properties of bone matrix and blood plasma are not cytological properties. ${ }^{18}$ It may be that certain anatomical properties supervene on cytological ones. But many anatomical properties of bones do not, of eyes do not, and so on.

This is a simple case of supervenience failure. There are too many parts of the body that are spatiotemporally and causally remote from cells, to count facts about those parts as being facts about cells. Even with a generous

\footnotetext{
${ }^{17}$ Virchow 1860

${ }^{18}$ Virchow was aware of this problem, but was committed to his cell theory. So he argued, implausibly, that the extracellular parts of the body were divided into "cell territories," over which cells had superintendence, much as Lake Superior is apportioned in part to the United States and in part to Canada.
} 
interpretation of the domain of cytology, it is not plausible that anatomy supervenes on it.

At the same time, we do not want to be artificially restrictive either. Consider, by contrast, the claim that brain anatomy supervenes on neurophysiology. In some ways, the same objections to Virchow's cell theory apply here. The brain is mostly made up of neurons and glial cells, but not entirely. There is a good deal in the brain going on outside of these cells: without extracellular neurotransmitters, the brain would do nothing. It seems similar to the anatomy/cytology case.

But there is a key difference. The problem with anatomy and cytology is simply that there is far too much to the body, apart from cells, to be plausibly counted as closely interacting with cells, and hence as part of the cytological property set. Even if cytology is not narrowly circumscribed, and includes more than just the intrinsic properties of cells, the noncellular parts of the body are too remote, and too much is too far out of causal contact with cells, to be reasonably counted in the domain of cytology. A reasonably expansive interpretation of the domain of neurophysiology gives a different result, in terms of its relation to brain anatomy. We might think of the neurophysiological property set as "intrinsic neural properties plus," where the "plus" includes properties of things neurons and glial cells are in close causal contact with. Despite the fact that the brain is not exhaustively composed of these cells, we can reasonably construe the neurophysiological property set, such that brain anatomical properties do supervene on it.

What counts as "close causal contact"? This is something we should understand reasonably and pragmatically. It must be something more than the objects that come in actual microphysical causal relations with individuals; otherwise, we could not include even the shortest causal chains. But it must be something less than indefinitely long or remote causal chains; otherwise, neurophysiological properties would include properties of the liver, and the cytological properties would include not only bone matrix but properties of cellphones. We know "close causal contact” when we see it.

If we do use a reasonable interpretation of these criteria for counting what 
is included as part of the cytological property set and of the neurophysiological one - intrinsic properties of the cells or neurons, plus intrinsic properties of the things they closely causally interact with — we generate the intuitive results that supervenience fails in the first case and succeeds in the second. Being charitable but reasonable about the supervenience base of the science, we make a pragmatic decision about what counts as "close causal contact," and hence about what the explanatory domain of the science is. With this pragmatic understanding, it is easy to see how anatomy can fail to supervene on cytology, but why it is reasonable to take brain anatomy to supervene on neurophysiology.

\subsection{Application to microeconomics}

Understanding what we mean by "microeconomic" will be somewhat more nuanced than what we mean by "cytological" or "neurophysiological." This is as we would expect it to be, given that in microeconomics we are not only concerned with physical properties of people, but their intentional properties and attitudes toward parts of the world. Still, the foregoing approach will be directly applicable to developing a reasonable understanding of the microeconomic property set.

In fact, there are some key challenges in identifying the microeconomic properties. Some of the most central are these:

(1) Although it would seem that microeconomics at least roughly has to do with individual people and their interactions, standard microeconomic models hardly limit themselves to this. For instance, they model households, firms, and governments as economic agents, in addition to individuals.

(2) When we consider actual microeconomic models, it is often unclear what objects they refer to. For instance, most contemporary microeconomic models refer to the future states of the world, in order to model decisions based on rational expectations. But of course, we are not (yet) causally influenced by future states of the world. Are facts about future states among the microeconomic ones? 
(3) A widely discussed point in the literature on methodological individualism is that we have attitudes toward institutions, inflation, and other macroentities. Do these fall inside or outside the domain of microeconomics, or are they evidence that we cannot even distinguish the property sets in the first place?

(4) Microeconomic properties seem limited to those "in the economic sphere.” It would seem that not all intrinsic properties of individual people should count as microeconomic ones, since many of these are irrelevant to economics altogether. On the other hand, it seems risky to exclude too many properties of individuals from the microeconomic property set, if that property set is to have a chance of being the supervenience base for macroeconomics.

It should really be the burden of the advocate of the supervenience of macroeconomics on microeconomics, and certainly on the advocate of microfoundations, to shed light on the microeconomic properties. Supervenience claims are often seen as the refuge of the reasonable antireductionists, the middle road for avoiding both an implausible dualism and an unattainable reductionism. But a supervenience claim can only have its punch if it is clear what sets of properties are being held to stand in that relation.

And these challenges are not straightforward to address. Part of the problem is that there is a divergence between the properties referred to in standard models, and those that can genuinely be considered as eligible for a microfoundations project. For instance, the fact that microeconomic models treat households, firms, governments, and other macroentities as economic agents makes it tempting to vastly expand what gets counted as individualistic. ${ }^{19}$ For instance, one might be inclined to consider households, firms, and governments as "individuals." The issue with this, at least for the microfoundationalist, is that it is of no use to anyone to have the

${ }^{19}$ Udehn (2001) criticizes Maarten Janssen along these lines, for his view that "households or firms may be regarded as 'individuals' relative to the aggregate level of the economy as a whole” (Janssen 1993, p. 7). 
microeconomic and macroeconomic property sets come out the same as one another. Certainly, the defender of supervenience does not want that. If we allow that most economically relevant properties of households, firms, governments, and so on are part of the microeconomic property set, then it is difficult to see what excludes every property that shows up even in a traditional macroeconomics textbook from counting as microeconomic.

If, for instance, we have a model of a nation's interest rates based on interactions between banks and firms treated as economic agents, then we can also find or construct a model of global interest rates based on interactions between nations treated as economic agents. This creates a conundrum as to whether the properties of nations ought to be included in the macroeconomic property set, as the former would suggest, or microeconomic property set, as the latter would.

To make sense of either the microfoundations project or a claim of supervenience, we need to distinguish two different conceptions of microeconomics. One loose conception is just a methodology making use of aggregative modeling methods. A generic type of model, or method for modeling, can be applied to more or less any kind of entity. For instance, nations, corporations, or government can be modeled as playing signaling games, or as standing in principal-agent relations, just as individual people can. However, this conception is too broad to apply to the aims of microfoundationalists like Lucas. If microeconomics is to be understood as potentially providing microfoundations for macroeconomics, then there must be at least some restrictions on the domain of microeconomic properties or objects. If all it takes for an entity to be microeconomic is that somewhere it is modeled as an economic agent, then microeconomic and macroeconomic properties are not likely to be distinct at all. In that case, microeconomics simply swallows macroeconomics, and there is no microfoundations project to be done.

Equally, if we understand microeconomics simply as a set of methods, which apply to objects at various levels depending on our explanatory interests, then any supervenience claim about microeconomics is empty. If the 
microeconomic properties include all the macroeconomic ones, then to say that macroeconomics supervenes on microeconomics is to say nothing. In short, there may be a conception of microeconomics that is a set of methodologies or model-types, without any restrictions about the entities those models are about. However, that conception is different from the one that microfoundationalists make use of, in looking for microeconomic foundations for macroeconomic phenomena. And that conception of microeconomics is different from the one referred to in a claim that macroeconomics supervenes on it.

A comprehensive account of microeconomic properties would demand a long and careful treatment. For our purposes, however, I propose that we cut through these problems, using the template we saw in cytology and neurophysiology. Analogous to the above treatments of cytology and neurophysiology, let $\mathrm{S}$ be the set of intrinsic properties of individual people "plus." Plus, that is, the intrinsic properties of the objects at the scale of the individual, ${ }^{20}$ which individuals are in close causal contact with. Just as in the other cases, "close causal contact" needs to be understood reasonably and pragmatically. To ensure that $\mathrm{S}$ is not artificially restricted, we should be generous about this understanding, just not ridiculously so.

Despite this vagueness about how to treat "close causal contact" for individuals, this set $\mathrm{S}$ is fairly clear and simple. It is plausibly a superset of the microeconomic properties - every intrinsic property of individuals is

${ }^{20}$ The idea of expanding the microeconomic properties to a bigger set $\mathrm{S}$ is just so as not to artificially restrict the individualistic properties to the intrinsic properties of individual people. But instead, to expand it to a set of properties that still count as individualistic but are not intrinsic. The problem with this generosity, however, is avoiding a kind of circularity. Despite wanting to admit non-intrinsic properties, we cannot define the superset S of "individualistic" properties in terms of the close contact of individuals with "individualistic" things. At an intuitive level, one would want to avoid institutions and other "macroeconomic entities." At the end of the day, these worries are a bit tangential to the argument against supervenience on $\mathrm{S}$, since the counterexamples for supervenience remain counterexamples even if institutions are included in S. Still, it is a difficult issue. I am grateful to an anonymous referee for pressing this point. 
included, as are the properties of parts of the world that they come in contact with. Implicitly, it understands microeconomics as being designed to model changes in the properties of individual people, as well as features of the world that trigger those changes. If a property of the world does not figure into a reasonably close chain of causes leading to or from changes in the properties of individuals, it is irrelevant to a microeconomic model.

This strategy may actually augment the microeconomic property set beyond its proper bounds. It will mean, for instance, that all intrinsic properties of individuals count as among the microeconomic ones. But it does not weaken our case against supervenience, for us to be extra-generous about what gets included in the microeconomic property set. We might understand it in this way: we construct a property set $\mathrm{S}$, which is plausibly a superset of the microeconomic properties. Then we argue that the macroeconomic properties do not supervene on $\mathrm{S}$. If $\mathrm{S}$ actually is a superset of the microeconomic properties, then a fortiori the macroeconomic properties do not supervene on the microeconomic ones. If, on the other hand, $\mathrm{S}$ is not a superset of the microeconomic properties - well, that is an opening for the advocate of supervenience. But it then puts the burden of delineating microeconomic properties in its proper place: on the defender of the supervenience claim.

Set $\mathrm{S}$ is a broad construal of microeconomic ontology. It is centered on individuals, but not restricted to properties that can be attributed to individuals. It will seem to many that this set is inclusive enough that macroeconomics will rather trivially supervene on it. Now let us show that even this microeconomic property set nonetheless falls short of determining the macroeconomic properties.

\section{Nonsupervenience of macroeconomics on $\mathrm{S}$}

It is commonly assumed that macroeconomic properties are simply aggregated properties of individuals, measured in some way or other. If this were the case, then supervenience on microeconomics would immediately follow. This assumption, however, is mistaken. Considering actual macroeconomic properties, it can be shown that they depend in part on factors 
that are neither the properties of individuals, even including their "wide" attitudes, nor that have close causal relations with individuals.

Microeconomics is a science of individuals and the things they interact with. But macroeconomic objects, properties, and facts are still "wider" than this. Macroeconomic properties, such as the liabilities of governments or the banking system, or the agency- and asset-backed securities in their balance sheets, play a key role in the macroeconomy. ${ }^{21}$ As I will discuss, these depend on features of the world we need not have any contact or interaction with.

To argue for non-supervenience, I will use a standard kind of test: I will set up two carefully constructed situations in which the supervenience base is identical, and that differ in only one factor outside the supervenience base. I have selected the following case because it is extremely simple, but it is just one of any number of examples that could be constructed for common macrovariables. The case, as with most such supervenience tests, is artificial. But it demonstrates how factors outside the microeconomic ones can nonetheless figure into the macroeconomic ones. Subsequently, I will point out that similar supervenience failure occurs in a wide variety of cases, apart from this artificial one.

\subsection{The hurricane case}

Consider a simplified economy for a small country in some storm-prone region, where the main responsibility of the government is to protect individuals from catastrophic storm damage. To keep expenditures under control, the government discriminates different levels of its responsibility for different types of storms. It enacts a policy that it will compensate individuals at two different rates:

1. For ordinary storm damage, the government pays $\$ 10,000$ per affected household

2. $\quad$ For damage from severe storms — defined as category 2 hurricanes or stronger - it pays $\$ 50,000$ per household.

${ }^{21}$ See, for instance, Erturk and Ozgur 2008. 
To set up the supervenience test, consider two different situations in which the storms causally affecting individuals and their possessions are indiscernible, yet where the storm is different.

Case A: The country is hit by a storm that is not a hurricane, and 1000 households are damaged.

Case B: The country is hit by a Category 2 hurricane, and 1000 households are still damaged, to exactly the same extent as in case A.

In case $\mathrm{A}$, the government accrues a $\$ 10 \mathrm{MM}$ obligation, while in $\mathrm{B}$, it accrues a $\$ 50 \mathrm{MM}$ obligation. Notice that this obligation is simply a legislated fact. Whether this fact obtains involves a physical criterion that is separate from the epistemic or other states of the individuals in the population. ${ }^{22}$ In case B, the presence of a hurricane sets government obligations at a higher level than they are set in case A, whether or not there are causal consequences for the individuals.

The obligations that the government incurs are a function in part of the impact the storm has on the population, that is, of the households that are damaged by the storm. However, they are also a function of the kind of storm it is, regardless of whether or not that difference has a causal effect on individuals. Putting the epistemology aside, and only considering the facts in the cases, in case A, the government has one level of obligation, and in case B, it has a different one. The government obligations accrue differently in the situations, based on factors that do not impinge on individuals. Thus a supervenience base that includes only the causal factors directly impinging on individuals will not determine the difference between these situations.

This is an artificial case, designed to show the metaphysical point. There are two natural reactions one might have. One is that this is not the way macroeconomic properties work: there is no possibility of a gap between the

${ }^{22}$ This property is not entirely independent of properties of individuals, but does not have to be, for it to fail to supervene globally on individualistic properties. An analogous case is facts about human anatomy: they are not entirely independent of facts about dermatology, and yet anatomical facts fail to supervene globally on dermatological ones. 
metaphysics and the epistemology of social facts. A different but related reaction is that even if there is such a difference, it is entirely irrelevant from a practical perspective. Whether or not a storm is a category 2 hurricane only has a practical effect inasmuch as it does affect individuals, and so where external facts fall outside the causal stream affecting individuals, they also fall outside of the practical scope of macroeconomics.

To respond to these reactions, let us turn to the very practical business of accounting. Constructing a simple balance sheet for the government over time will show that a difference in the "metaphysical status" of a government obligation at time t can have a practical impact later on, even if it has absolutely no epistemic effect at time $t$.

\subsection{Practical implications of the metaphysical difference}

To perform this accounting exercise, let us consider the government balances over time, leaving the facts as they are in the first few years, and then adding to the case that eventually the inhabitants of the storm-prone country do learn of the difference between the situations, a couple of years following the storm. The following table shows the economic effects of situation A. 


\begin{tabular}{|c|c|c|c|c|c|c|c|c|}
\hline $\begin{array}{l}\text { Year } \\
\text { Event }\end{array}$ & $\begin{array}{c}0 \\
\text { Normal } \\
\end{array}$ & $\begin{array}{c}1 \\
\text { Storm } \\
\end{array}$ & $\begin{array}{c}2 \\
\text { Calm } \\
\end{array}$ & $\begin{array}{c}3 \\
\text { Initial } \\
\text { payment }\end{array}$ & $\begin{array}{c}4 \\
\text { Acquire } \\
\text { information }\end{array}$ & $\begin{array}{c}5 \\
\text { Normal } \\
\end{array}$ & $\begin{array}{c}6 \\
\text { Normal } \\
\end{array}$ & $\begin{array}{c}7 \\
\text { Normal } \\
\end{array}$ \\
\hline Interest rate & $4 \%$ & $4 \%$ & $4 \%$ & $4 \%$ & $4 \%$ & $4 \%$ & $4 \%$ & $4 \%$ \\
\hline $\begin{array}{l}\text { Government } \\
\text { obligations }\end{array}$ & & & & & & & & \\
\hline (\$MM) & - & 10.0 & 10.4 & - & - & - & - & - \\
\hline $\begin{array}{l}\text { Tax levied and } \\
\text { collected }(\$ M M)\end{array}$ & - & - & 10.4 & - & - & - & - & - \\
\hline $\begin{array}{l}\text { Government } \\
\text { disbursements } \\
\text { (\$MM) }\end{array}$ & - & - & - & 10.8 & - & - & - & - \\
\hline $\begin{array}{l}\text { Current surplus } \\
\text { (deficit) }(\$ \mathrm{MM})\end{array}$ & - & - & 10.4 & - & - & - & - & - \\
\hline $\begin{array}{l}\text { Productivity } \\
\text { growth }\end{array}$ & $3 \%$ & $2 \%$ & $2 \%$ & $4 \%$ & $3 \%$ & $3 \%$ & $3 \%$ & $3 \%$ \\
\hline
\end{tabular}

Table 1. Some macroeconomic statistics, in situation A

In year 1 , there is a storm, which generates $\$ 10 \mathrm{MM}$ of government obligations. In year 2, $\$ 10.4 \mathrm{MM}$ of taxes are levied, to take into account interest on the obligations, and payments are made to the households in year 3, again adjusting for interest. In year 4 , the weather committee returns with the results that it was indeed a tropical storm rather than a hurricane, and so that is the end of the story, and productivity growth, which had a temporary hit and small surge from years 1 and 2 to year 3, subsequently returns to its normal $3 \%$.

Table 2 shows the sequence of events for situation B. Here, there is a hurricane in year 1 , so the government accrues \$50MM in obligations, but the individuals are in the same epistemic state as in case A. Thus until year 4 , taxes and disbursements are the same as in situation A. In the meantime, however, the obligation has kept growing, and then in years 5 and 6 , upon receiving the information that the storm had been a hurricane, it levies additional taxes to pay its obligations, and then pays them in year 6, with interest accruing all the time. Its total disbursements, then, are \$10.8MM in year 2 and \$46.8MM in 


\begin{tabular}{|c|c|c|c|c|c|c|c|c|}
\hline $\begin{array}{l}\text { Year } \\
\text { Event }\end{array}$ & $\begin{array}{c}0 \\
\text { Normal }\end{array}$ & $\begin{array}{c}1 \\
\text { Storm }\end{array}$ & $\begin{array}{c}2 \\
\text { Calm }\end{array}$ & $\begin{array}{c}3 \\
\text { Initial } \\
\text { payment }\end{array}$ & $\begin{array}{c}4 \\
\text { Acquire } \\
\text { information }\end{array}$ & $\begin{array}{c}5 \\
\text { Normal }\end{array}$ & $\begin{array}{c}6 \\
\text { Normal }\end{array}$ & $\begin{array}{c}7 \\
\text { Normal }\end{array}$ \\
\hline Interest rate & $4 \%$ & $4 \%$ & $4 \%$ & $4 \%$ & $4 \%$ & $4 \%$ & $4 \%$ & $4 \%$ \\
\hline $\begin{array}{l}\text { Government } \\
\text { obligations }\end{array}$ & & & & & & & & \\
\hline (\$MM) & - & 50.0 & 52.0 & 43.3 & 45.0 & 46.8 & - & - \\
\hline $\begin{array}{l}\text { Tax levied and } \\
\text { collected }(\$ M M)\end{array}$ & - & - & 10.4 & - & - & 46.8 & - & - \\
\hline $\begin{array}{l}\text { Government } \\
\text { disbursements } \\
\text { (\$MM) }\end{array}$ & - & - & - & 10.8 & - & - & 48.7 & - \\
\hline $\begin{array}{l}\text { Current surplus } \\
\text { (deficit) }(\$ M M)\end{array}$ & - & - & 10.4 & - & - & 46.8 & - & - \\
\hline $\begin{array}{l}\text { Productivity } \\
\text { growth }\end{array}$ & $3 \%$ & $2 \%$ & $2 \%$ & $4 \%$ & $3 \%$ & $1 \%$ & $4 \%$ & $3 \%$ \\
\hline
\end{tabular}

Table 2. Some macroeconomic statistics, in situation $B$

This is the natural way for accounting for what has happened over this period. It is not irrelevant, for the determination of government disbursement over the time period, what the government obligations are in each year. In year 6 , government obligations are $\$ 46.8 \mathrm{MM}$ because the obligation did not begin in the $6^{\text {th }}$ year, but rather was being accrued from year 1 .

Since the information about the hurricane is only acquired in year 4 , there is no change in disbursements until then, no change in revenues, and no hit to productivity. In fact, the accountants in year 3 do not realize that the first three columns in Table 2 are the correct ones to describe their own situation, and that those in Table 1 are mistaken. In later years, they would need to retroactively restate the balance sheet they had mistakenly recorded in earlier years. That does not mean, however, that the first columns of Table 1 were ever correct for them - only that they did not realize it. And the correct facts about the liability, those represented in Table 2, have repercussions. The metaphysical fact of the value of the macrovariable - i.e., the actual value of the government obligation - is precisely what matters in determining what the subsequent 
payment schedule is.

\subsection{Analysis and generalization}

The accounting exercise described in $\S 4.2$ illustrates that the facts about the government's year 1 liabilities matter, even if no one knows those facts until year 4 . The facts themselves are not exhaustively determined by the epistemic states of individuals, or by their intrinsic properties, or by things they are in close causal contact with. Despite the microeconomic facts being indiscernible for the first few years in the two situations, the facts about the government's respective liabilities differ. It is not mysterious what makes the facts differ, nor is it mysterious why we set up the factual conditions for the accrual of government liabilities the way we do. In microeconomic explanations, we investigate the narrow cascading of causes as individuals interact with one another, affecting and being affected by the world as they come in contact with it. Typical macroeconomic properties, however, do not exhaustively depend on the narrow facts about individual people and the stuff they interact with. Rather, we set up macroeconomic properties to track a wide variety of features of the world that are of importance to us. They are important to us in part because they typically and eventually do have an effect on us. But these effects are not among the application conditions for the properties. The criteria for the government to have the \$50MM liability are not arbitrary, and not entirely independent of properties in set S. But they partly depend on properties outside that set.

To be sure, microeconomics may in principle be capable of giving a narrow causal explanation for the actions of individuals, the disbursements, and so on, described in the situations above. But microeconomics is not in the business of generating models that make use of the same extrinsic properties that macroeconomic models do. (A similar contrast arises in "internalist" versus “externalist” explanations of psychological phenomena.) ${ }^{23}$ Consider how a microeconomic model of the described situations would be constructed. Only

${ }^{23}$ Cf. Fodor 1980 and the large subsequent literature. 
factors directly causally impinging on individuals would be employed, so there will not be a "government obligation" variable that changed according to the facts about the storm in year 1 . The model would not reflect any difference between the cases until at least year 4 . Once the knowledge of the status of the storm reached the population, then it could model the effects of that knowledge on the actions taken by the government. It would do so not by getting the changing value of the macrovariable correct, however. Rather, it would introduce a new set of proxy variables to indicate the epistemic states that change in year $4 .^{24}$

In the accounting case I have described, the macroproperties of situations A and B diverge in year 1 , while the microeconomic properties diverge only in year 4 and afterwards. A microeconomic model need not account for any difference between the situations before year 4 , since individual psychology and behavior coincides until then. But a model that tracks the macroproperties will reflect their change in the first year.

One strategy that may be tempting, to rescue supervenience, is to insist that in the accounting case I have described, the macroproperties change in year 1 in virtue of the change in microproperties in year 4 . And if the fact of the matter about the storm had never been discovered (as in the pure case I described earlier), there would have been no difference in the macroproperties. This

${ }^{24}$ Christian List has pointed out to me that certain versions of game theory would admit "moves" of nature as part of an account of these situations. What is admissible in game theory in general, however, is not necessarily part of an individual-centered microeconomic supervenience base. For instance, game theory models the strategic interaction among nations, govenments, firms, etc., as freely as it does of individuals. In the case of the "natural move," the properties of game theoretic agents can involve extrinsic properties that are not direct causes affecting individuals. For the theorist wanting to use game theory as a way of delineating a supervenience base for microeconomics, it will not do to sanction just any extraindividualistic factor. Otherwise she risks trivializing the distinction between macroeconomics and microeconomics. The game theorist must delineate an appropriate supervenience base, just as the other microfoundations theorists must. It may be possible to expand microeconomics to include such factors. My thanks to an anonymous referee for stressing this point. 
strategy is rather desperate and unlikely. It is hard to see how it could consistently be maintained that every macroeconomic fact must be known, in order to be a macroeconomic fact. There may be epistemic requirements on macroeconomic facts and properties in general. It may be, for instance, that in order for something to be a liability, we are explicitly aware of the conditions for a thing to have the property being a liability. But that does not mean that we must know in every particular case whether such properties hold, in order for them to hold at all. If that were right, then we would never need to go back and restate a balance sheet.

This is a simplified case, and deals with a simple obligation of a government, rather than the more complicated macroproperties that are part of macroeconomic theory. But this sort of determination of the value of macrovariables is quite general. The same principles can be applied to the properties of entities at many levels, from households and firms to agencies, governments, nations, and global markets. The supervenience failure in this case is simply a consequence of the liability being a function of what happens in the world at large.

Many other macroeconomic properties are similar. It has, for instance, become increasingly clear that the real economy is substantially affected by the financial sector, and the instruments it employs, such as securities and derivative instruments. The hurricane insurance contract I described above is only a simple example of one such instrument, whose properties depend on facts about the world at large. Many if not most such instruments depend on similar facts - repos, mortgage-backed obligations, credit default obligations, and so on. This is only one category of examples, but it is already a large one. My aim in this paper has been to demonstrate an example of supervenience failure, and to point out a direction where we need to further investigate the ontology of macroeconomic properties. The mistake microfoundationalists seem to make is to assume that macroeconomic properties are either simple or gerrymandered aggregates of microeconomic ones. On scrutiny, there is no good reason why this should be so. 


\section{Conclusion}

In the end, it is of course the burden of the supervenience theorist to clarify just what the supervenience claim is supposed to be, and hence to delineate the microeconomic property set. It is somewhat surprising that more attention has not been paid to the task. Here I have addressed a conception of microeconomics as placing at least some restrictions on the domain of microeconomic properties or objects - that is, taking the objects of microeconomics to be individual people and objects at the scale of the individual that they come in close causal contact with. This conception, I think, is consistent with the intentions and models of much mainstream microeconomic theory. If the foregoing arguments are correct, then microeconomics is built to solve a different problem than to found macroeconomics.

With the failure of supervenience, a fortiori there is no complete microeconomic explanation of all the macroeconomic phenomena, since the microeconomic properties do not even determine the macroproperties. Moreover, it is unlikely to be a straightforward matter to supplement the ontology of microeconomics such that it will exhaustively determine macroproperties and yet remain basically individualistic.

The failure of supervenience creates equal difficulties for current agentbased computational economics (ACE) models as it does for analytic ones, such as DSGE models. A good ACE model of a phenomenon will have to decide if it fundamentally wants to operate with a microeconomic ontology or not. Inasmuch as it does, it may successfully simulate the actions of agents, but it will not suffice for generating the values of macroeconomic properties. Inasmuch as the generation of macroeconomic properties is the goal, on the other hand, a computer model will not be simply agent-based. 


\section{References}

Arrow, K. J. and F. Hahn (1971). General Competitive Analysis, San Francisco: Holden-Day.

Bennett, K. (2004). "Global Supervenience and Dependence," Philosophy and Phenomenological Research 68, pp. 510-529.

Currie, G. (1984). "Individualism and Global Supervenience," British Journal for the Philosophy of Science 35, pp. 345-358.

Erturk, K. and G. Ozgur (2008). "The Decline of Traditional Banking and Endogenous Money," Department of Economics Working Paper Series, University of Utah 2008-16.

Epstein, B. (2009). "Ontological Individualism Reconsidered," Synthese 166, pp. 187-213.

Fine, K. (1994). "Essence and Modality," Philosophical Perspectives 8, pp. 116.

Fodor, J. A. (1980). "Methodological Solipsism Considered as a Reseach Strategy in Cognitive Psychology," Behavioral and Brain Sciences 3, pp. 63-109.

Hartley, J. E. (1997). The Representative Agent in Macroeconomics, London: Routledge.

Hausman, D. (1992). The Inexact and Separate Science of Economics, Cambridge: Cambridge University Press.

Hoover, K. (1995). "Is Macroeconomics for Real?," The Monist 78, pp. 235257.

- (2001a). Causality in Macroeconomics, Cambridge: Cambridge University Press.

_ (2001b). The Methodology of Empirical Macroeconomics, Cambridge: 
Cambridge University Press.

(2006). "A NeoWicksellian in a New Classical World: The Methodology of Michael Woodford's Interest and Prices," Journal of the History of Economic Thought 28, pp. 143-149.

_ (2009). "Microfoundations and the Ontology of Macroeconomics," in: H. Kincaid and D. Ross, eds., Oxford Handbook of Philosophy of Economics, Oxford: Oxford University Press.

Janssen, C. W. (1993). Microfoundations: A Critical Inquiry, London: Routledge.

Kallestrup, J. (2006). "The Causal Exclusion Argument," Philosophical Studies 131, pp. 459-485.

Kim, J. (1984). "Concepts of Supervenience," Philosophy and Phenomenological Research 45, pp. 153-176.

(1987). "'Strong' and 'Global' Supervenience Revisited," Philosophy and Phenomenological Research 45, pp. 153-176.

_ (1998). Mind in a Physical World, Cambridge: MIT Press.

_ (2001). "Mental Causation and Consciousness: The Two Mind-Body Problems for the Physicalist," in: C. Gillett and B. Loewer, eds., Physicalism and its Discontents, Cambridge: Cambridge University Press.

Kincaid, H. (1997). Individualism and the Unity of Science, Lanham: Rowman and Littlefield.

Kincaid, H. (1998). "Supervenience," in: J.B. Davis, D. W. Hands and U. Mäki, eds., The Handbook of Economic Methodology, Cheltenham: Edward Elgar.

Kirman, A. (1992). "Whom or What Does the Representative Agent 
Represent?," Journal of Economic Perspectives 6, pp. 117-136.

Lucas, R. E. (1976). "Econometric Policy Evaluation: A Critique," in: K. Brunner and A. H. Meltzer, eds., The Phillips Curve and Labor Markets, Amsterdam: North-Holland, pp. 19-45.

McLaughlin, B. P. and K. Bennett (2005). "Supervenience," in: E. Zalta, ed., Stanford Encyclopedia of Philosophy.

Nelson, A. (1986). "New Individualistic Foundations for Economics," Noûs 20, pp. 469-490.

Pettit, P. (2003). "Groups with Minds of Their Own," in: F. Schmitt, ed., Socializing Metaphysics, Lanham, MD: Rowman and Littlefield.

Reiss, J. (2004). "Review of The Methodology of Empirical Macroeconomics by Kevin Hoover," Economics and Philosophy 20, pp. 226-233.

Shagrir, O. (2002). "Global Supervenience, Coincident Entities, And AntiIndividualism," Philosophical Studies 109, pp. 171-196.

Sider, T. (1999). "Global Supervenience and Identity Across Times and Worlds," Philosophy and Phenomenological Research 59, pp. 913937.

Virchow, R. L. K. (1860). Cellular Pathology: As Based Upon Physiological and Pathological Histology, London: John Churchill. 